\title{
Lysyl oxidase inhibition via $\beta$-aminoproprionitrile hampers human umbilical vein endothelial cell angiogenesis and migration in vitro
}

\author{
LIN SHI $^{1 *}$, NING ZHANG ${ }^{1 *}$, HETAO LIU $^{1}$, LEI ZHAO ${ }^{1}$, JING LIU $^{1}$, JUAN WAN $^{2}$, \\ WENYI WU ${ }^{3}$, HETIAN LEI ${ }^{3}$, RONGQING LIU ${ }^{2}$ and MEI HAN ${ }^{1}$ \\ ${ }^{1}$ Department of Pathogenic Biology and Immunology, School of Basic Medical Sciences, Ningxia Medical University; \\ ${ }^{2}$ Department of Rheumatology and Immunology, The General Hospital of Ningxia Medical University, Yinchuan, \\ Ningxia 750004, P.R. China; ${ }^{3}$ Schepens Eye Research Institute of Massachusetts Eye and Ear, \\ Department of Ophthalmology, Harvard Medical School, Boston, MA 02114, USA
}

Received August 13, 2017; Accepted January 17, 2018

DOI: $10.3892 / \mathrm{mmr} .2018 .8508$

\begin{abstract}
Lysyl oxidase(LOX) is an enzyme that oxidizes lysine residues in collagens and elastin. It stabilizes or remodels the extracellular matrix and basement membrane of blood vessels. Current oncology studies have revealed that LOX is upregulated in invasive cancer cells and bolstered cell movement, and LOX was observed to promote the angiogenesis and migration of endothelial cells. In the present study, angiogenesis and migration were examined in human umbilical vein endothelial cells (HUVECs). Following cell treatment with 0.1-0.4 mM $\beta$-aminoproprionitrile (BAPN), a specific inhibitor of LOX, angiogenesis was analyzed with a fibrin gel in vitro angiogenesis assay kit and migration was examined via a Boyden Chamber assay. Angiogenesis-associated gene expression was investigated with a microarray assay and confirmed with reverse transcription-quantitative polymerase chain reaction (RT-qPCR). The results showed that HUVEC angiogenesis substantially increased in the presence of vascular endothelial growth factor (VEGF), basic fibroblast growth factor (bFGF)
\end{abstract}

Correspondence to: Professor Mei Han, Department of Pathogenic Biology and Immunology, School of Basic Medical Sciences, Ningxia Medical University, 1160 Shengli Street, Yinchuan, Ningxia 750004, P.R. China

E-mail: hanmei0708@126.com

Dr Rongqing Liu, Department of Rheumatology and Immunology, The General Hospital of Ningxia Medical University, 804 Shengli Street, Yinchuan, Ningxia 750004, P.R. China

E-mail: liurongqing1964@163.com

${ }^{*}$ Contributed equally

Key words: angiogenesis, migration, lysyl oxidase, human umbilical vein endothelial cell, myeloid progenitor inhibitory factor 1, phospho-mitogen-activated protein kinase, phospho-protein kinase B and phorbol 12-myristate 13-acetate (PMA). In addition, LOX inhibition blocked the angiogenesis stimulated by VEGF bFGF and PMA, and the inhibition of LOX reduced the migration of HUVECs. Furthermore, the microarray and RT-qPCR revealed that BAPN downregulated myeloid progenitor inhibitory factor 1 , and western blot analysis demonstrated that BAPN decreased the phosphorylation of MAPK and Akt, suggesting that the specific inhibitor of LOX, BAPN, may serve as an alternative strategy for preventing angiogenesis.

\section{Introduction}

Angiogenesis is a process by which the primitive vasculature is expanded and remodeled to form the networks of large and small vessels that have the interconnecting, branching pattern of the mature vascular system. The neovascularization develops from endothelial cells that originate from antecedent vessels (1). Throughout the sprouting process, endothelial cells deteriorate the concealed basement membrane, move into the adjacent tissue, proliferate, and assemble into tubes (2). Soluble factors and cell-cell and cell-matrix interactions are necessary for the established vasculature to acclimate to varying demands $(1,3)$. Angiogenesis plays a critical role in physiological and pathological processes, including halting ischemic damage caused by stroke (4), cancer migration (5) and pannus formation in rheumatoid arthritis (6). The lesion of microvessel basement membrane is critical for the blood brain barrier (BBB) damage that happens following ischemic stroke $(7,8)$. Well-acknowledged experimental data and clinical results of these microvascular wall changes are due to edema caused by endothelial integrity loss after extravasations of noncellular blood elements as haemorrhages (9).

Lysyl oxidase (LOX) can oxidize lysine residues in collagens and elastin, catalyse lysine-derived cross-links, and stabilize the extracellular matrix and basement membrane of blood vessels in normal tissues $(10,11)$. Current oncology outcomes have revealed that LOX is expressed in prolifically spreading tumor cells, and it promoted cancer metastasis $(12,13)$. Clinical and experimental evidence singles out LOX as a possible 
therapeutic target (14). Endothelial cells also express LOX. One study suggested that the LOX genes upregulated in tumor endothelial cells (TECs) compared to normal endothelial cells, and LOX could be a TEC marker (15). The lysyl oxidase inhibitor $\beta$-aminopropionitrile (BAPN) impedes tumor angiogenesis and glioblastoma multiforme development in a mouse orthotopic brain tumor model (16). A previous study of our group indicated that inhibition of LOX attenuated the microvascular density in the synovial membranes of collageninduced arthritis rats (17). In the present study we found that BAPN inhibited angiogenesis and migration of human umbilical vein endothelial cells (HUVECs).

\section{Materials and methods}

Cell culture. HUVECs were purchased from the China Center for Type Culture Collection (Wuhan, China), and cultured in Dulbecco's modified Eagle's medium (DMEM) supplemented with $10 \%$ fetal bovine serum (FBS), 2 mM L-glutamine, $5 \mathrm{U} / \mathrm{ml}$ penicillin $\mathrm{G}, 5 \mu \mathrm{g} / \mathrm{ml}$ streptomycin sulfate (Invitrogen, Carlsbad, CA, USA). The present study was approved by the Ethical Committee of The General Hospital of Ningxia Medical University (Yinchuan, China; registration no. 2016-230).

Enzyme-linked immunosorbent assay (ELISA). HUVECs (1x10 $/$ well) were seeded on 96-well plates, incubated for $24 \mathrm{~h}$ to allow for attachment to the surface of plate, then starved by incubating another 24-48 h in serum-free DMEM. The cellfree supernatants were harvested for measuring the secreted LOX using an ELISA kit according to the manufacturer's recommendations (SEC580Ra; Cloud-Clone Corp., Houston, TX, USA). Optical density values of the samples were used to calculate the concentrations of all of the samples.

Fibrin gel angiogenesis analysis. A fibrin gel in vitro angiogenesis assay kit (ECM630; Chemicon, Temecula, CA, USA) was used to evaluate tube formation of HUVECs in 96-well plates. A fibrinogen mixture was dispensed into the well with thrombin. Finally, the plate was placed at $37^{\circ} \mathrm{C}$ for $30 \mathrm{~min}$ for polymerization. We added $100 \mu \mathrm{l}$ HUVECs (with the cell concentration of $5 \times 10^{4}$ cells $/ \mathrm{ml}$ ) in basal medium (DMEM supplemented with $1 \%$ BSA and antibiotics) with vascular endothelial growth factor (VEGF; Genentech, South San Francisco, CA, USA) $10 \mathrm{ng} / \mathrm{ml}$, basic fibroblast growth factor (bFGF; Becton-Dickinson Labware, Bedford, MA, USA) $10 \mathrm{ng} / \mathrm{ml}$, phorbol 12-myristate 13-acetate (PMA; Sigma Chemical Co., St. Louis, MO, USA) $30 \mathrm{ng} / \mathrm{ml}$ with or without BAPN (0.1, 0.2, $0.4 \mathrm{mM}$ ) (Sigma-Aldrich; Merck KGaA, Darmstadt, Germany). They were grown at $37^{\circ} \mathrm{C}$ overnight in the tissue-culture incubator. After removing the culture medium we added $30 \mu \mathrm{l}$ of fibrinogen per well in each medium of the noted wells, followed by $20 \mu \mathrm{l}$ thrombin placed in every well. Then, the plate was placed in a $37^{\circ} \mathrm{C}$ incubator for $5 \mathrm{~min}$ to polymerize. Images were captured using a Zeiss microscope (magnification, x100) after a week. Vessels were quantified by counting branch points in 6 random view-fields per well and the values were averaged.

Cell migration assay. Boyden Chamber assay (Corning Costar, New York, NY, USA) was used to assess cell migration. After cells were grown to $80 \%$ confluence, they were harvested. $600 \mu \mathrm{l}$ of medium containing $10 \%$ FBS without or with BAPN $(0.1,0.2,0.3$ and $0.4 \mathrm{mM})$ was added into each well of the 24-well (?) plate. Then, we placed $1 \times 10^{5}$ cells in $100 \mu \mathrm{l}$ serum-free medium with or without BAPN into the insert wells of $8 \mu \mathrm{l}$ pore membrane Boyden Chambers. After incubating for $24 \mathrm{~h}$ at $37^{\circ} \mathrm{C}$, the unattached cells were removed. Then, cells were fixed by methanol for $5 \mathrm{~min}$, washed once with PBS, and stained with $0.05 \%$ Giemsa stain. We quantified the cells that moved to the lower sides of the membrane by counting in 5 random visual fields (magnification, x200) for each well under a light microscope.

Microarray assay. HUVECs were cultured with or without BAPN $(0.4 \mathrm{mM})$ for $24 \mathrm{~h}$ in serum-free medium. Total RNA was extracted using Tri Reagent (Molecular Research Center, Inc. Cincinnati, OH, USA) based on the manufacturer's instructions. The RNA concentration was evaluated by an optical density (OD) ratio of 260:280 and with gel electrophoresis. The cDNA was synthesized by reverse transcription of the RNA. The cDNA microarrays were generated with a SPBIO2000 robotic arrayer, and it had 1080 cDNA clones. Fluorescence intensities, produced by $\mathrm{Cy} 5$ or $\mathrm{Cy} 3$ impaired to the target sequences on the microarray slides, were quantified with a ScanArray 5000 laser confocal microscope equipped scanning system (General Scanning, Watertown, MA, USA) using the necessary excitation and emission filters. The signal from every impaired cDNA target on the microarray slide was found, and the expression ratio among the experimental and reference samples (Cy5/Cy3 ratio) was established with ImaGene version 3.0 software (Biodiscovery, Los Angeles, California, USA). Microarray analysis was conducted in triplicate, and the $\mathrm{Cy} 5 / \mathrm{Cy} 3$ ratio values are the averages.

Reverse transcription-quantitative polymerase chain reaction (RT-qPCR). Total RNA was isolated using the TRI Reagent from the HUVECs treated with and without BAPN as described above. The purity of the RNA preparation was checked by the $260 / 280 \mathrm{~nm}$ ratio. Reverse transcription was conducted with $5 \mu \mathrm{g}$ total RNA using random hexamer primers with the SuperScript ${ }^{\mathrm{TM}}$ First-Strand Synthesis System for RT-PCR kit (Invitrogen Life Technologies, Carlsbad, CA, USA) as detailed by the company. PCR primers were designed with IDT OligoAnalyzer 3.0 (Integrated DNA Technologies, Coralville, Iowa, USA). The forward primer for myeloid progenitor inhibitory factor 1 (MPIF-1) gene (Ass no.: NM_005064) is: 5'-TGCCTCATGCTTGTTACTGC-3', and the reverse primer is: 5'-TGATCCGTGTGTCCAGCTTC-3'. The RNA analysis was performed with DyNAmo ${ }^{\mathrm{TM}} \mathrm{HS}$ SYBR-Green qPCR kit (MJ Bioworks, Inc., South San Francisco, CA, USA). All PCR reactions were performed in $20 \mu \mathrm{l}$ reaction volumes. PCR conditions were $95^{\circ} \mathrm{C}$ for $30 \mathrm{sec}$ for denaturation, and 45 cycles of amplification at $95^{\circ} \mathrm{C}$ for $5 \mathrm{sec}$ and at $60^{\circ} \mathrm{C}$ for $20 \mathrm{sec}$, modified based on previously described (18). Amplification and detection were performed using the DNA Engine Opticon 2 Continuous Fluorescence Detection System (MJ Bioworks, Inc.). Relative quantification of mRNA levels was conducted with the standard curve method, with amplification of firststrand cDNA in regular PCR. The standard curves were established with 4 dilutions (100,000, 10,000, 1,000 and 100) 

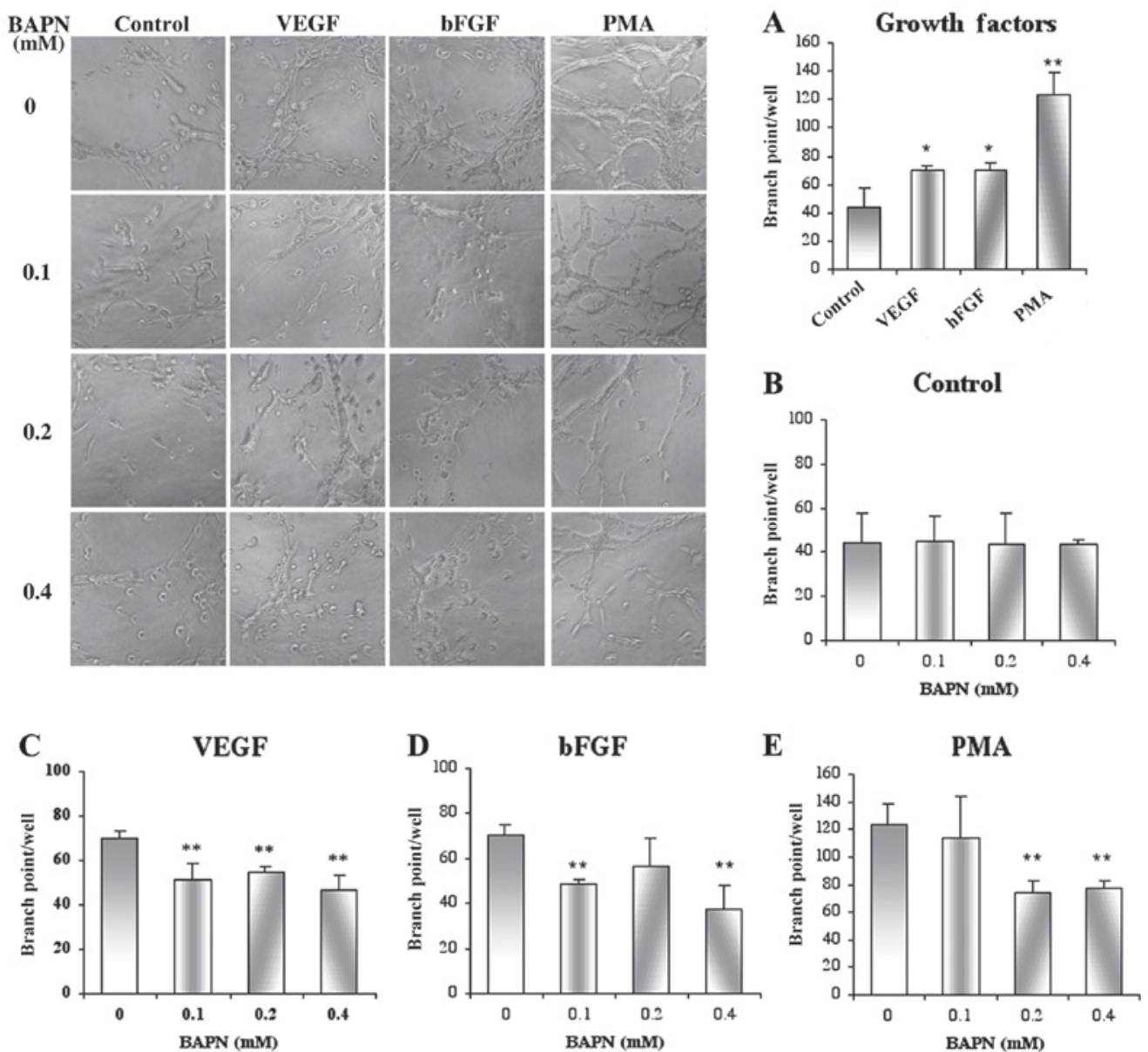

Figure 1. BAPN inhibited angiogenesis in HUVECs induced by VEGF, bFGF and PMA in vitro (magnification, x100). (A) HUVECs form capillary-like sprouts in fibrin gels. Branch points increased following the induction of HUVECs with VEGF, bFGF and PMA. (B) Branch points had no differences following HUVEC treatment with BAPN in the absence of proangiogenic agents. The formation of branch points induced by (C) VEGF, (D) bFGF and (E) PMA decreased with BAPN treatment. " $\mathrm{P}<0.05$ and ${ }^{* *} \mathrm{P}<0.01$ vs. control/0 mM BAPN. BAPN, $\beta$-aminoproprionitrile; HUVECs, human umbilical vein endothelial cells; VEGF, vascular endothelial growth factor; bFGF, basic fibroblast growth factor; PMA, phorbol 12-myristate 13-acetate.

of cDNA, and the samples were then run in duplicate with the primers.

Westernblotanalysis.Cells were lysed on the plate with CelLytic mammalian tissue lysis/extraction reagent, supplemented with a proteinase inhibitor cocktail (Sigma, St. Louis, MO, USA). The protein concentration was established using the Bradford assay with bovine serum albumin as a standard. Total $30 \mu \mathrm{g}$ proteins in each lane were isolated on $10 \%$ sodium dodecyl sulfate-polyacrylamide gel electrophoresis gels. The samples were then move to nitrocellulose paper. Following blockage with 5\% skim milk, the blots were incubated with phospho-p44/42 MAPK (Thr202/Tyr204, ERK1/ERK2) monoclonal antibody (9106; Cell Signaling Technology, Inc., Danvers, MA, USA) at 1:2,000, phospho-Akt (Ser473) monoclonal antibody (587F11, 4051, Cell Signaling Technology, Inc.) at 1:1,000 in $5 \%$ milk in Tris-buffered saline-Tween overnight at $4{ }^{\circ} \mathrm{C}$. The membranes were then incubated with horseradish peroxidaseconjugated secondary antibodies (1:500; RPN2133; Amersham, Arlington Heights, IL, USA) for $1 \mathrm{~h}$ at room temperature. The blots were then incubated with the enhanced chemiluminescence (ECL) technique (Amersham). Chemiluminescence was evaluated through exposing the membranes to Kodak X-Omat films (Eastman Kodak, Rochester, NY, USA).
Statistical analysis. The data are displayed as means \pm standard deviations (SD). Statistical analyses were performed with SPSS statistical software (version 20.0; IBM, Armonk, NY, USA). Continuous variables that were normally distributed were compared with one-way analysis of variance (ANOVA) followed by a Student-Newman-Keuls (SNK) post hoc test. A value of $\mathrm{P}<0.05$ was considered significant.

\section{Results}

LOX secretion from HUVECs. We first examined the LOX expressions in HUVECs before we studied the role of BAPN on HUVECs. Supernatants of HUVECs were harvested after incubating for 24 and $48 \mathrm{~h}$ to measure LOX. The LOX concentrations were $53.12 \mathrm{pg} / \mathrm{ml}$ in the 24-h supernatant and $94.72 \mathrm{pg} / \mathrm{ml}$ in the 48 -h supernatant.

$B A P N$ inhibits angiogenesis induced by VEGF, FGF and $P M A$. HUVECs were induced to form anastomosing networks of capillary-like tubes in fibrin gel. Imaging was captured after a week, and the branch points in 6 random view-fields per well were counted and the values were averaged (Fig. 1). In the absence of growth factors, capillary sprout formation was minimal (control, $0.0 \mathrm{mM}$ BAPN), and there were no 


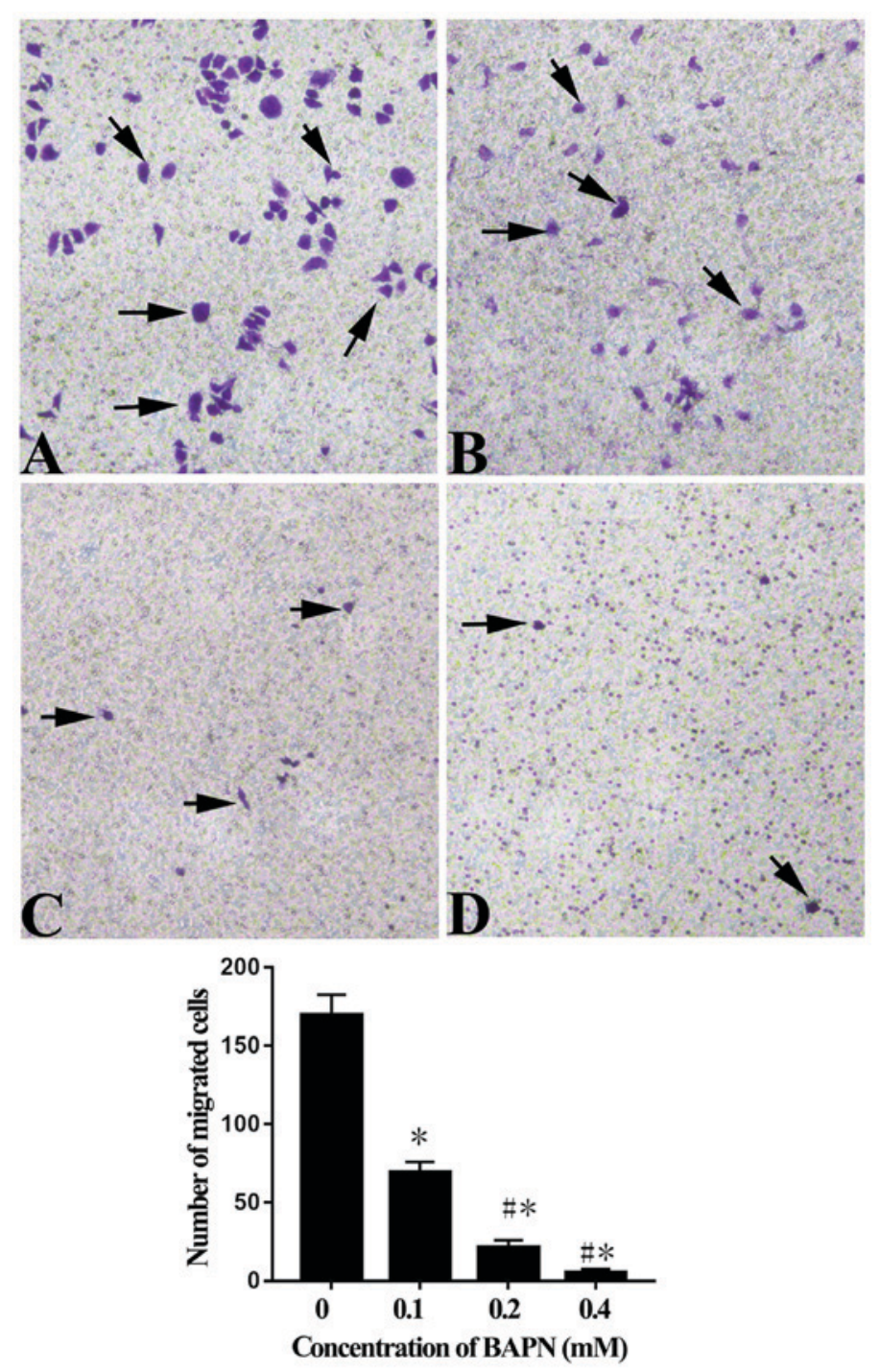

Figure 2. HUVEC migration was measured via a Boyden Chamber assay (magnification, $\mathrm{x} 200$ ). The effects of BAPN on HUVEC migration were tested in the presence or absence of BAPN. (A) No BAPN treatment, (B) treatment with $0.1 \mathrm{mM} \mathrm{BAPN}$, (C) treatment with $0.2 \mathrm{mM}$ BAPN and (D) $0.4 \mathrm{mM}$ BAPN. Black arrows indicate the migrated HUVECs. ${ }^{*}<0.05$ vs. no BAPN treatment $(0 \mathrm{mM}$ BAPN); $\mathrm{P}<0.05$ vs. $0.1 \mathrm{mM}$ BAPN treatment. HUVECs, human umbilical vein endothelial cells; BAPN, $\beta$-aminoproprionitrile.

significant changes after adding BAPN which inhibits LOX in the basal medium group (control with $0.1,0.2$ and $0.4 \mathrm{mM}$ BAPN). VEGF, bFGF and PMA induced obvious sprouting of HUVECs $(\mathrm{P}<0.05)$. Importantly, BAPN $(0.1,0.2$ and $0.4 \mathrm{mM})$ significantly inhibited angiogenesis induced by VEGF, bFGF and PMA compared with control $(\mathrm{P}<0.05)$.

$B A P N$ inhibits cell migration induced by FBS. Since angiogenesis greatly relies on endothelial cell motility, we evaluated the impact of BAPN on movement of HUVECs using an in vitro assay (Fig. 2). The results showed that when FBS significantly induced migration of HUVECs migration, BAPN at $0.1,0.2$ and $0.4 \mathrm{mM}$ significantly inhibited cell migration of HUVECs $(\mathrm{P}<0.05)$.

Upregulated and downregulated genes expression after BAPN treatment. We implemented a microarray assay to determine the changes of gene expression of HUVECs treated with BAPN. As shown in Tables I and II, BAPN upregulated 178, and downregulated 29 angiogenesis-related genes. The upregulated genes, including NADH dehydrogenase (ubiquinone) flavoprotein 1 and thymidine kinase, were involved in activities such as cell signal transduction and enzyme activity. The downregulated genes included AH-receptor mRNA and thrombin receptor mRNA. Noticeably, BAPN suppressed expression of MPIF-1 (hmrp-2a), a human chemokine, in HUVECs.

Quantitation of Hmrp-2a (MPIF-1) by RT-qPCR. Since the microarray assay showed a significant change in MPIF-1 mRNA, we investigated the expression of MPIF-1 in HUVECs using RT-qPCR. The results showed that MPIF-1 mRNA reduced by 2 -fold, from $1,250 \pm 35$ copies (control) to $638 \pm 52$ copies in BAPN-treated cells, and that there was significantly different between these two groups $(\mathrm{P}<0.05)$.

BAPN inhibition of phosphorylation of MAPK1/2 and Akt. In order to understand the mechanism by which BAPN abrogated angiogenesis, we investigated whether BAPN would affect phosphorylation of MAPK and Akt in HUVECs because 
Table I. Angiogenesis-associated genes upregulated following $\beta$-aminoproprionitrile treatment.

\begin{tabular}{|c|c|}
\hline Activity & Gene \\
\hline Enzyme activity & $\begin{array}{l}\text { NADH dehydrogenase (ubiquinone) flavoprotein } 1(51 \mathrm{kDa}) \\
\text { Enolase } 2 \text { ( } \gamma \text { neuronal) } \\
\text { Human thymidine kinase mRNA, complete cds cytochrome b-245, } \alpha \text { polypeptide } \\
\text { HMT1 (hnRNP methyltransferase, } S \text {. cerevisiae)-like } 1\end{array}$ \\
\hline Binding activity & $\begin{array}{l}\text { NADH dehydrogenase (ubiquinone) flavoprotein } 1 \text { ( } 51 \mathrm{kDa}) \\
\text { Human mRNA for TGF- } \beta \text { superfamily protein, completed cds } \\
\text { Human eukaryotic translation elongation factor } 1 \Delta \text { (guanine nucleotide exchange) } \\
\text { Human, ADP-ribosylation factor 4-like, clone MGC:1801 IMAGE:3509618, mRNA }\end{array}$ \\
\hline Signal transducer activity & $\begin{array}{l}\text { Human mRNA for KIAA1398 protein, partial cds } \\
\text { NADH dehydrogenase (ubiquinone) flavoprotein } 1(51 \mathrm{kDa}) \\
\text { Human mRNA for TGF- } \beta \text { superfamily protein, complete cds } \\
\text { HMT1 (hnRNP methyltransferase, } S \text {. cerevisiae)-like } 1\end{array}$ \\
\hline Transporter activity & $\begin{array}{l}\text { Human mRNA for KIAA } 1398 \text { protein, partial cds } \\
\text { ATP-binding cassette, sub-family F (GCN20), member } 2\end{array}$ \\
\hline Structural molecule activity & $\begin{array}{l}\text { Human cytokeratin } 8 \text { mRNA, complete cds } \\
\text { Human epidermal cytokeratin } 2 \text { mRNA, complete cds } \\
\text { Human, tubulin } \alpha 1 \text {, clone MGC:2321 IMAGE:3528520, mRNA, complete cds } \\
\text { Human, Similar to actin, } \gamma 1 \text {, clone MGC:15377 IMAGE:3940861, mRNA }\end{array}$ \\
\hline Motor activity & $\begin{array}{l}\text { Human, Similar to actin, } \gamma 1 \text {, clone MGC: } 15377 \text {, IMAGE:3940861 } \\
\text { Human mRNA for enteric smooth muscle } \gamma \text {-actin } \\
\text { Human mRNA for cytoskeletal } \gamma \text {-actin }\end{array}$ \\
\hline Extracellular & $\begin{array}{l}\text { Human mRNA for TGF- } \beta \text { superfamily protein, complete cds interferon-stimulated protein, } \\
15 \mathrm{kDa} \text { a disintegrin-like and metalloprotease (reprolysin type) with thrombospondin typ } \\
\text { insulin-like growth factor-binding protein } 4 \\
\text { Human mRNA for plasma gelsolin follistatin-like } 3 \text { (secreted glycoprotein) human } \\
\text { pro-urokinase mRNA, complete cds }\end{array}$ \\
\hline
\end{tabular}

ATP, adenosine triphosphate; cds, coding DNA sequence; hnRNP, heterogeneous ribonucleoprotein particle; HMT1, protein-arginine $\Omega-N$ methyltransferase 1; TGF, transforming growth factor; NADH, nicotinamide adenine dinucleotide.
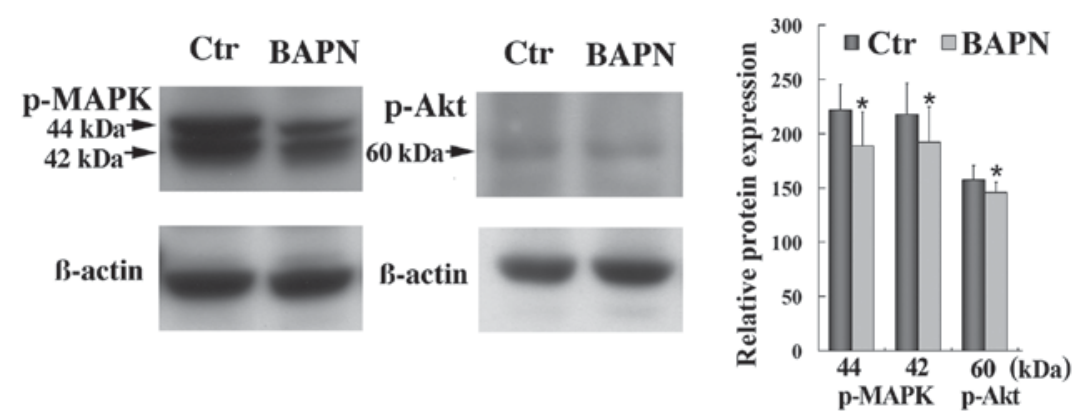

Figure 3. Western blot analysis of p-MAPK and p-Akt. Following human umbilical vein endothelial cells treatment with BAPN, the levels of p-MAPK (44 and $42 \mathrm{kDaa})$ and p-Akt decreased. $\mathrm{P}<0.05$ vs. Ctr (0 mM BAPN). p-, phosphorylated; MAPK, mitogen-activated protein kinase; Akt, protein kinase B; BAPN, $\beta$-aminoproprionitrile; $\mathrm{Ctr}$, control.

both of MAPK and Akt involve in angiogenesis. The results showed that after treatment with $0.2 \mathrm{mM}$ BAPN for $48 \mathrm{~h}$, both MAPK1/2 and Akt phosphorylation was reduced (Fig. 3). These results suggest that BAPN may be able to serve as alternative strategy to prevent angiogenesis via inhibiting LOX.

\section{Discussion}

Angiogenesis is a process of forming new capillaries from current blood vessels, and it is required for organ development, wound healing and pathological diseases, such as tumor 
Table II. Angiogenesis-associated genes downregulated following $\beta$-aminoproprionitrile treatment.

Activity

Enzyme activity

Signal transducer activity

Binding activity

Structural molecule activity

Transporter activity

Transcription regulator activity

Cell adhesion molecule activity
Gene

Human bisphosphate 3'nucleotidase mRNA, complete cds

Human, proteasome (prosome, macropain) 26S subunit,ATPase, 2, clone MGC:3004IM

Human plasma membrane calcium ATPase isoform 3x/b mRNA, complete cds

Human phogrin mRNA, complete cds

Human ALK-3 mRNA

Human mRNA for CDK8 protein kinase

Human mRNA for KIAA0205 gene, complete cds

Human chemokine (hmrp-2a) mRNA, complete cds

Human AH-receptor mRNA, complete cds

Human ALK-3 mRNA

Human thrombin receptor mRNA, complete cds

Human chemokine (hmrp-2a) mRNA, complete cds

Human plasma membrane calcium ATPase isoform 3x/b mRNA, complete cds

Human AH-receptor mRNA, complete cds

Human I-plastin mRNA, complete cds

Human thrombin receptor mRNA, complete cds

Human thrombospondin 2 mRNA, complete cds

Human I-plastin mRNA, complete cds

Human plasma membrane calcium ATPase isoform 3x/b mRNA, complete cds

Human AH-receptor mRNA, complete cds

Human thrombospondin 2 mRNA, complete cds

ATP, adenosine triphosphate; cds, coding DNA sequence; ALK-3, activin receptor-like kinase 3; CDK8, cyclin-dependent kinase 8; HMRP-2a, C-C motif chemokine ligand 23; AH, aryl hydrocarbon.

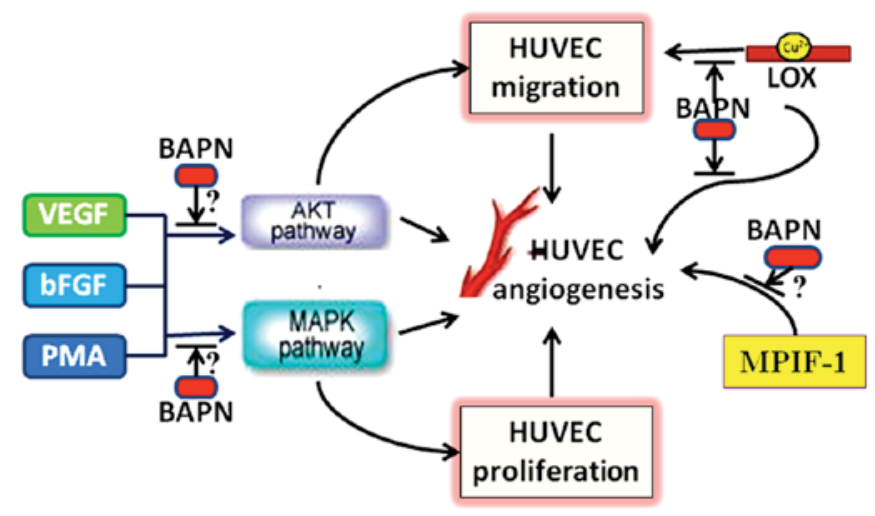

Figure 4. Schematic of the potential pathway. VEGF, bFGF and PMA stimulated HUVECs proliferation, migration and angiogenesis. MPIF-1 is also a pro-angiogenic molecule. BAPN suppressed HUVEC angiogenesis and migration. The effects of BAPN may be inhibiting the chemokine MPIF-1, MAPK and Akt signal pathways; however, it is still not clear whether BAPN inhibits the MPIF-1, MAPK and Akt signal pathways directly or indirectly. VEGF, vascular endothelial growth factor; bFGF, basic fibroblast growth factor; PMA, phorbol 12-myristate 13-acetate; HUVECs, human umbilical vein endothelial cells; MPIF-1, myeloid progenitor inhibitory factor 1; LOX, lysyl oxidase; MAPK, mitogen-activated protein kinase; Akt, protein kinase B.

advancement. Blocking of angiogenesis is potential therapeutic strategy for preventing tumor or ischemic stroke $(5,19)$. The administration of proangiogenic agents, such as bFGF, VEGF, to animals with stroke significantly reduced neurological dysfunction (20). The main components that control the angiogenic process are the extracellular matrix (ECM), integrins and angiogenic cytokines. Angiogenic stimuli bring about endothelial cells to experience migration, lumen composition, and branching throughout the development of new capillaries.

LOX is a copper-conditional, emitted amine oxidase that oxidatively deaminates the e-amino team of specific peptidyl lysine and hydroxylysine residues of collagen and of lysine in elastin. The ensuing peptidyl aldehydes condense immediately with peptidyl aldehydes found in the local vicinity, or with unreacted e-amino groups, to create intermolecular crosslinkages that hold steady the fibrous types of collagen and elastin $(10,11)$. LOX can retain the integrity of the extracellular matrix and basement membrane of blood vessels. BAPN is a potent irreversible LOX inhibitor that links to the functional area of LOX, and it is enzymatically transferred to a reactive type, which derivatizes the enzyme. Thus, BAPN has been utilized to impede the functions of lysyl oxidase isoenzymes $(21,22)$. The present study investigated the impacts of LOX on angiogenesis and cell migration.

VEGF, bFGF and PMA stimulate endothelial cell proliferation, migration, and assembly. VEGF controls activities of endothelial cells, including proliferation, differentiation, permeability, vascular tone, and vasoactive molecules 
generation. VEGF binds to VEGFR-2, and the receptor tyrosine are phosphorylated (23). Growth and differentiation factor, bFGF plays a significant role in development, angiogenesis and neoplastic transformation. It may be generated by stromal and endothelial cells $(24,25)$. The protein kinase C activator PMA has been documented to be a tumor inducer, and it provides adequate mitogen used in cells culture (26). In this research, we found that HUVECs secrete LOX, but there were no significant changes after adding BAPN to the cells. In addition, VEGF, bFGF and PMA facilitated angiogenesis of HUVECs. Angiogenesis of HUVECs was attenuated when adding BAPN. Thus, BAPN inhibited HUVECs angiogenesis induced by VEGF, bFGF and PMA. In the presence of FBS, BAPN (0.1 to $0.4 \mathrm{mM})$ significantly impeded HUVEC migration (Fig. 4).

In our previous study (17), the type II collagen-induced arthritis model of rats were established. BAPN was intraperitoneally injected to inhibit LOX activity. The results showed the microvascular density in the synovial membrane was reduced after BAPN treatment, indicated that LOX promotes synovial angiogenesis in CIA rats. This result is consistent with the results in this paper on HUVECs. Furthermore, to explore the effects of LOX on angiogenesis, we cultured gastric cancer cell line MGC-803 and BGC-823 and inhibit LOX with BAPN. The results suggested LOX can promote the formation of vasculogenic mimicry and migration of gastric cancer cells. Inhibition of LOX by BAPN can decreased the formation of vasculogenic mimicry and migration (the result has not been published).

Angiogenesis is a step-wise course, with following steps: A rise in vascular permeability, degradation of the area matrix, proliferation and migration of endothelial cells, and then, stabilization and ending of angiogenesis. Thus, numerous genes must take part in this process $(1,3)$. Beneath typical conditions, a balance existings between angiogenic inducers and angiogenic inhibitors that holds the angiogenic course in line and protects against unnecessary vascularization of tissues. Since BAPN inhibited HUVECs migration and angiogenesis, we supposed that BAPN downregulates pro-angiogenesis promoter genes and upregulates angiogenesis suppression genes. We conducted a microarray assay in which we investigated 207 angiogenesis-implicated genes and contrasted the angiogenesis-related gene expression following BAPN treatment with no BAPN treatment in HUVECs. The results showed that BAPN downregulated 29 genes, upregulated 178 genes.

MPIF-1, also known as myeloid progenitor inhibitory factor 1, CC Chemokine ligand 23 (CCL23) and CK $\beta 8$, was initially determined from a human aortic endothelial cell library and the human monocytic cell line THP-1 $(27,28)$. It shows chemotactic activity on resting $\mathrm{T}$ lymphocytes, monocytes and neutrophils through $\mathrm{C}-\mathrm{C}$ chemokine receptor type 1 (CCR1). In addition, MPIF-1 is a pro-angiogenic molecule that bolsters chemotactic movement and differentiation of endothelial cells $(29,30)$. We discovered that MPIF-1 decreased 2 -folds after BAPN treatment. We also performed RT-qPCR of this molecule, and the outcomes were in agreement with the microarray analysis, which demonstrated the accuracy of the microarray experiments. Our data indicated that BAPN could impede MPIF-1 in HUVECs.
It has been reported that MPIF-1 transduces the chemotaxis signal via the PLC, PKC $\delta$, and $\mathrm{NF}-\kappa \mathrm{B}$ (31). VEGF receptor activation can prompt the initiation of the MAPK/ERK cascade through Raf stimulation, prompting cell proliferation and survival through gene expression and phosphatidylinositol3-kinase(PI3K)/Akt pathway, which can induce vasopermeability, and angiogenesis (32). Furthermore, we found that BAPN decreased phosphorylation of the MAPK1/2 and Akt, suggesting that BAPN impedes VEGF-, bFGF- and PMA-induced angiogenesis via suppressing the activation of MAPK1/2 and Akt (Fig. 4).

In summary, we examined the impacts of inhibiting LOX by BAPN on HUVECs' angiogenesis and migration, and alterations in angiogenesis-related gene expression via a microarray evaluation, and we also performed RT-qPCR to validate the alteration. Furthermore, we performed western blotting to study which pathway BAPN was used. The major finding of the present study is that BAPN suppressed HUVECs angiogenesis and migration, and the effects of BAPN took place by inhibiting chemokine MPIF-1, MAPK, and Akt signal pathways. The present study suggests that LOX is a target for inhibiting angiogenesis.

\section{Acknowledgements}

This research was backed with financial assistance provided by the National Natural Science Foundation of China (grant. nos. 81260314 and 81260459), the West China Top Class Discipline Project in Basic Medical Sciences, Ningxia Medical University (grant. no. NXYLXK2017B07), and the Open project of 'doctor degree construction' of Ningxia Medical University (KF2010-23).

\section{References}

1. Wong VW and Crawford JD: Vasculogenic cytokines in wound healing. Biomed Res Int 2013: 190486, 2013.

2. Moon JJ, Saik JE, Poché RA, Leslie-Barbick JE, Lee SH, Smith AA, Dickinson ME and West JL: Biomimetic hydrogels with pro-angiogenic properties. Biomaterials 31: 3840-3847, 2010.

3. Eelen G, de Zeeuw P, Simons M and Carmeliet P: Endothelial cell metabolism in normal and diseased vasculature. Circ Res 116: 1231-1244, 2015.

4. Hoang S, Liauw J, Choi M, Choi M, Guzman RG and Steinberg GK: Netrin-4 enhances angiogenesis and neurologic outcome after cerebral ischemia. J Cereb Blood Flow Metab 29: 385-397, 2009.

5. Weis SM and Cheresh DA: Tumor angiogenesis: Molecular pathways and therapeutic targets. Nat Med 17: 1359-1370, 2011.

6. Gibofsky A: Overview of epidemiology, pathophysiology, and diagnosis of rheumatoid arthritis. Am J Manag Care 18 (13 Suppl): S295-S302, 2012.

7. Wang CX and Shuaib A: Critical role of microvasculature basal lamina in ischemic brain injury. Prog Neurobiol 83: 140-148, 2007.

8. Gautam J, Zhang X and Yao Y: The role of pericytic laminin in blood brain barrier integrity maintenance. Sci Rep 6: 36450, 2016.

9. Knapton AD, Zhang J, Sistare FD and Hanig JP: The use of in situ perfusion of the rat mesentery as a model to investigate vascular injury directly induced by drugs. Methods Find Exp Clin Pharmacol 32: 489-497, 2010.

10. Kagan HM and Li W: Lysyl oxidase: Properties, specificity, and biological roles inside and outside of the cell. J Cell Biochem 88: 660-672, 2003

11. Mäki JM: Lysyl oxidases in mammalian development and certain pathological conditions. Histol Histopathol 24: 651-660, 2009. 
12. Erez N: Cancer: Opening LOX to metastasis. Nature 522: 41-42, 2015.

13. Perryman L and Erler JT: Lysyl oxidase in cancer research. Future Oncol 10: 1709-1717, 2014.

14. Rodríguez C, Rodríguez-Sinovas A and Martínez-González J: Lysyl oxidase as a potential therapeutic target. Drug News Perspect 21: 218-224, 2008

15. Osawa T, Ohga N, Akiyama K, Hida Y, Kitayama K, Kawamoto T, Yamamoto $\mathrm{K}$, Maishi N, Kondoh $\mathrm{M}$, Onodera Y, et al: Lysyl oxidase secreted by tumour endothelial cells promotes angiogenesis and metastasis. Br J Cancer 109: 2237-2247, 2013.

16. Mammoto T, Jiang A, Jiang E, Panigrahy D, Kieran MW and Mammoto A: Role of collagen matrix in tumor angiogenesis and glioblastoma multiforme progression. Am J Pathol 183: 1293 $1305,2013$.

17. Wang F, Wan J, Li Q, Zhang M, Wan Q, Ji C, Li H, Liu R and Han M: Lysyl oxidase is involved in synovial hyperplasia and angiogenesis in rats with collagen-induced arthritis. Mol Med Rep 16: 6736-6742, 2017.

18. Sharma-Bhandari A, Park SH, Kim JY, Oh J and Kim Y: Lysyl oxidase modulates the osteoblast differentiation of primary mouse calvaria cells. Int J Mol Med 36: 1664-1670, 2015.

19. Yin KJ, Hamblin M and Chen YE: Angiogenesis-regulating microRNAs and ischemic stroke. Curr Vasc Pharmacol 13: 352-365, 2015.

20. Liu N, Zhang Y, Fan L, Yuan M, Du H, Cheng R, Liu D and Lin F: Effects of transplantation with bone marrow-derived mesenchymal stem cells modified by Survivin on experimental stroke in rats. J Transl Med 9: 105, 2011.

21. Aciksari K, Yanar HT, Hepgul G, Ozucelik DN, Yanar F, Agcaoglu O,Eser M, Tanriverdi G, Topacoglu H, Ayvaci BM, et al: The effect of Beta-aminopropionitrile and prednisolone on the prevention of fibrosis in alkali esophageal burns: An experimental study. Gastroenterol Res Pract 2013: 574260, 2013.

22. Miana M, Galán M, Martínez-Martínez E, Varona S, Jurado-López R, Bausa-Miranda B, Antequera A, Luaces M, Martínez-González J, Rodríguez C and Cachofeiro V: The lysyl oxidase inhibitor $\beta$-aminopropionitrile reduces body weight gain and improves the metabolic profile in diet-induced obesity in rats. Dis Model Mech 8: 543-551, 2015.

23. Shibuya M: Vascular endothelial growth factor and its receptor system: Physiological functions in angiogenesis and pathological roles in various diseases. J Biochem 153: 13-19, 2013.

24. Li R, Wu H, Xie J, Li G, Gu R, Kang L, Wang L and Xu B: Syndecan-4 regulates the bFGF-induced chemotactic migration of endothelial cells. J Mol Histol 47: 503-509, 2016.
25. Fus ŁP and Górnicka B: Role of angiogenesis in urothelial bladder carcinoma. Cent European J Urol 69: 258-263, 2016.

26. Padma D and Bhat KM: A comparison between phorbol 12 myristate 13 acetate and phorbol 12, 13 dibutyrate in human melanocyte culture. J Clin Diagn Res 10: GC01-GC04, 2016.

27. Patel VP, Kreider BL, Li Y, Li H, Leung K, Salcedo T, Nardelli B, Pippalla V, Gentz S, Thotakura R, et al: Molecular and functional characterization of two novel human $\mathrm{C}-\mathrm{C}$ chemokines as inhibitors of two distinct classes of myeloid progenitors. J Exp Med 185: 1163-1172, 1997.

28. Youn BS, Zhang SM, Brox meyer HE, Cooper S, Antol K, Fraser M Jr and Kwon BS: Characterization of CKbeta8 and CKbeta8-1: Two alternatively spliced forms of human beta-chemokine, chemoattractants for neutrophils, monocytes, and lymphocytes, and potent agonists at CC chemokine receptor 1. Blood 91: 31183126, 1998.

29. Hwang J, Son KN, Kim CW, Ko J, Na DS, Kwon BS, Gho YS and Kim J: Human CC chemokine CCL23, a ligand for CCR1, induces endothelial cell migration and promotes angiogenesis. Cytokine 30: 254-263, 2005.

30. Poposki JA, Uzzaman A, Nagarkar DR, Chustz RT, Peters AT, Suh LA, Carter R, Norton J, Harris KE, Grammer LC, et al: Increased expression of the chemokine CCL23 in eosinophilic chronic rhinosinusitis with nasal polyps. J Allergy Clin Immunol 128: 73-81.e4, 2011.

31. Kim J, Kim YS and Ko J: CK beta 8/CCL23 induces cell migration via the Gi/Go protein/PLC/PKC delta/NF-kappa B and is involved in inflammatory responses. Life Sci 86: 300-308, 2010.

32. Das AM, Pescatori M, Vermeulen CE, Rens JA, Seynhaeve AL, Koning GA, Eggermont AM and Ten Hagen TL: Melanomas prevent endothelial cell death under restrictive culture conditions by signaling through AKT and p38 MAPK/ERK-1/2 cascades. Oncoimmunology 5: e1219826, 2016.

(i) $($ ) This work is licensed under a Creative Commons Attribution-NonCommercial-NoDerivatives 4.0 International (CC BY-NC-ND 4.0) License. 